\title{
MODIFIED PERIODONTAL EXPLORER FOR EXPANSION SCREW ACTIVATION
}

\author{
Dr. T. Srinivasan, Dr. R. Satish, Dr. R. Suresh, Dr. Sujith Sivarajan
}

1. Reader, Department of Orthodontics, Adhiparasakthi Dental College and Hospital. Melmaruvathur, Tamil Nadu.

2. Associate Professor, Department of Orthodontics, Adhiparasakthi Dental College and Hospital. Melmaruvathur, Tamil Nadu.

3. Senior lecturer, Department of Orthodontics, Adhiparasakthi Dental College and Hospital. Melmaruvathur, Tamil Nadu.

4. Senior lecturer, Department of Orthodontics, Adhiparasakthi Dental College and Hospital. Melmaruvathur, Tamil Nadu.

\section{CORRESPONDING AUTHOR}

Dr. T. Srinivasan,

Adhiparasakthi Dental College and Hospital,

Melmaruvathur, Kanchipuram District,

Tamilnadu, India-603319,

E-mail: Srimdc@yahoo.co.in,

Ph: 9109841611886.

INTRODUCTION: Accidents with expansion screw activation keys are reported in the literature ${ }^{1,2}$. A simple method to prevent such accident is to use a modified periodontal explorer as a key for expansion screw activation. A no.17 periodontal explorer (fig 1) is cut at its first terminal bend (fig 2). The second section is bent more vertically to the long axis of the shaft (fig 3 ). This part which is tapered and stiff enough to activate the screw is tried extra orally into the screw. It is further trimmed in such a way that only a mm of instrument can project through the screw hole (fig 4). Now a safe key for activating the maxillary expansion screw is ready to use (fig 5). Once the patient's parent or guardian successfully repeat the activation procedure in office, the instrument can be given to them for home use.

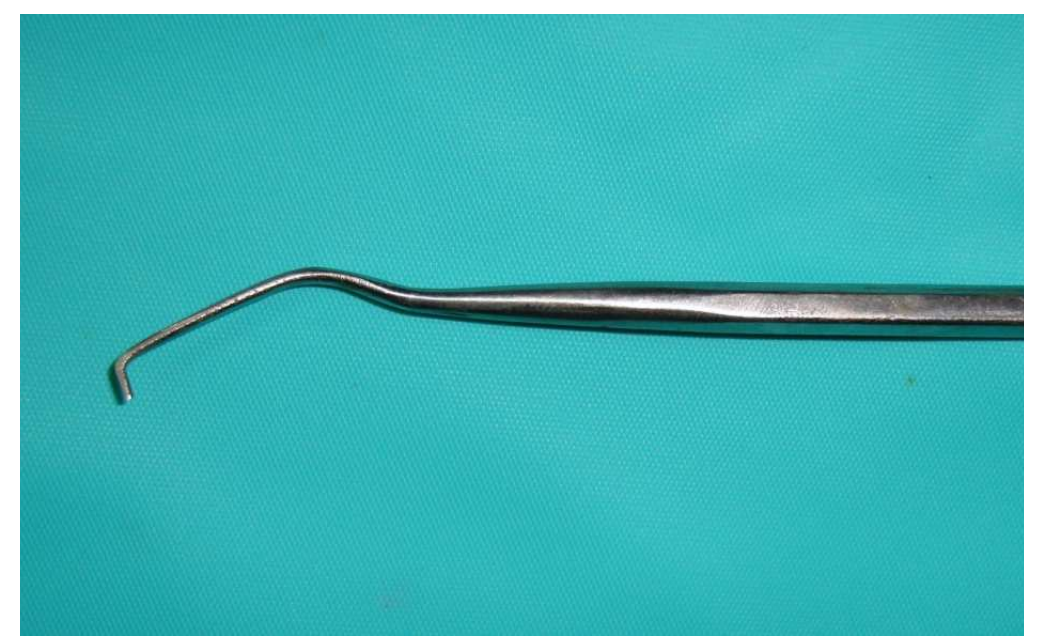

Journal of Evolution of Medical and Dental Sciences/Volume1/ Issue3/July-Sep $2012 \quad$ Page 269 

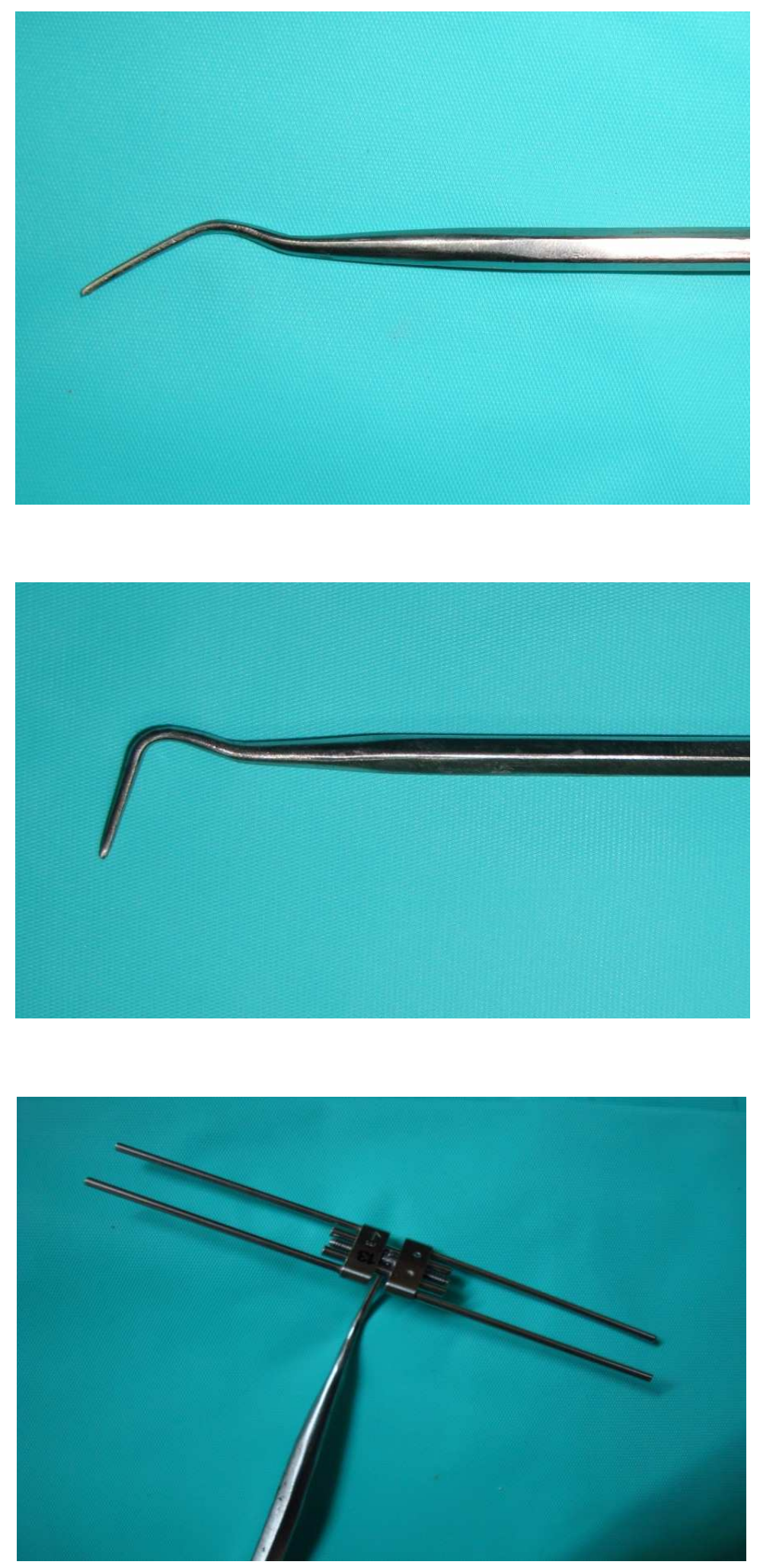


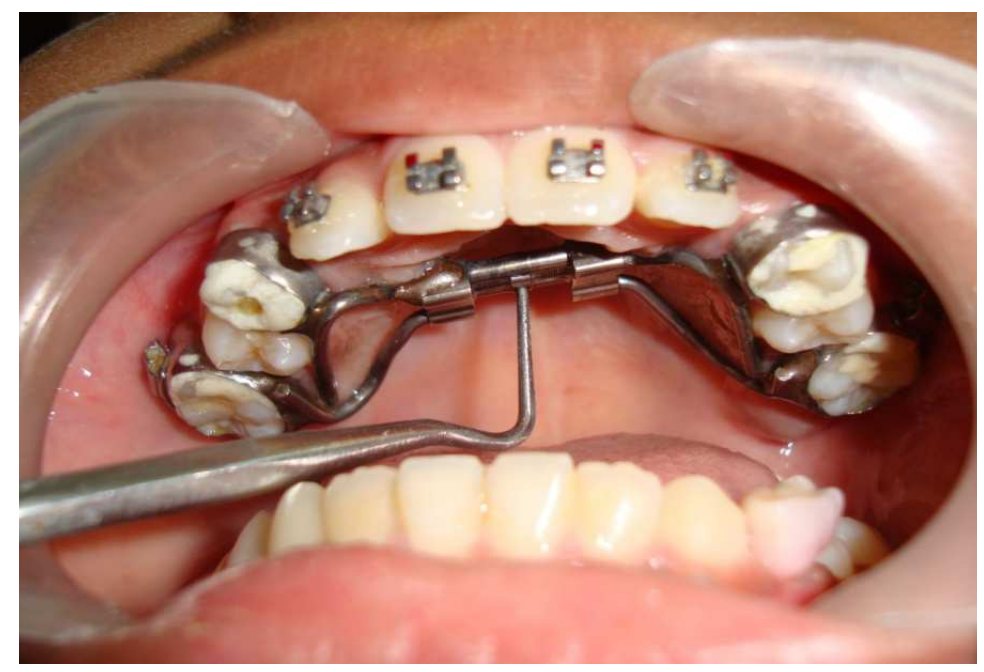

\section{REFERENCES:}

1. Nazif MM, Ready MA. Accidental swallowing of orthodontic expansion key: report of two cases. ASDC J Dent child 1983; 50:126-127

2. Sfondrini MF, Cacciafesta V, Lena A. Accidental ingestion of a rapid palatal expander. J Clin Orthod 2003; 37: 201-202 